\title{
A User Friendly Software for Rigid Pavement Design
}

\author{
Aydın Kıcı ${ }^{a}$, Mesut Tı̆̆demir ${ }^{* *}$ \\ Department of Civil Engineering, Faculty of Engineering, Suleyman Demirel University, Cunur, Isparta, Turkey \\ ${ }^{*}$ E-mail address: mtigdemir.acd@ yahoo.com \\ ORCID numbers of authors: \\ 0000-0001-9741-4995 ${ }^{a}$, 0000-0002-5303-2722 ${ }^{b}$
}

Received date: August 2017

Accepted date: November 2017

\begin{abstract}
Concrete pavements as concrete road slab, appear as a strong alternative for flexible superstructures especially because of their low cost for maintenance and repair and the high performance they show under heavy axle loads. The design of these concrete road slabs is quite different from the traditional concrete and reinforced concrete structures'design. In the design for this kind of pavements, traffic conditions should be defined properly and considered an addition to the concrete and platform properties. There have been designing methods developed based on both experimental and mechanic foundations for concrete pavements. The most important ones of these methods are AASHTO (1993) and PCA (1984). In both design methods, it's significant to know the maximum deflections and maximum strains the vehicles' loads cause on the pavement. The calculation of this maximum deflections and maximum strains can be done via the finite element method or the closed formulas which have been developed by Westergaard. In this study, a user-friendly software has been developed based on AASHTO 1993, PCA 1984 design methods and Westergaard formulas. Thanks to this software, the user who wants to design the concrete pavement as concrete road slab can obtain the essential parameters automatically by entering the required data for the design.
\end{abstract}

Keywords: PCA1984, AASHTO 1993, Rigid pavement, Westergaard Analysis, Visual Programming

\section{Introduction}

Rigid pavements are built with Portland Cement Concrete. The first concrete pavement was built in Bellefontaine, Ohio in 1891 and the pavement was only $3 \mathrm{~m}$ wide and $67.1 \mathrm{~m}$ long. [1] From the first time they were built in Ohio their use is increasing day by day and only in the USA the concrete pavement's length has exceeded $100.000 \mathrm{~km}$. Concrete pavements which meet both public and private institutions' needs with being strong and its durability being high, is a versatile paving implementation. Thanks to the high rigidity of the concrete, concrete pavements can transmit the applied loads to the sub-grade in larger and homogeneous areas. By this means, it forms an alternative for the flexible superstructure [2-3].

Concrete pavements are extensively used as a superstructure element as road slab for highways, airports, industrial grounds, streets, parking areas etc. If designed correctly and constructed well, they are capable to service for dozens of years without any maintenance cost [2]. In terms of cost, concrete pavement's initial cost is higher than pavement but it needs less maintenance throughout its lifetime [3]. 
Sound engineering is considerably important at this point. Because if the pavement's thickness is designated more than it should be, its initial manufacturing cost will increase. [2,3,4] In contrast, if the thickness of the pavement is thinner than it should be, its maintenance cost will increase. Therefore, maximum effort should be shown for the design of concrete roads.

Design methods which are used for concrete pavement design are generally based on mechanical and experimental sources. Another criterion used in concrete pavement designs is experience. Therefore, because of the criteria of concrete pavement designs that have to be taken into consideration come from different sources, it's more complicated than expected. To facilitate this complication, design methods that have an experimental and mechanic infrastructure which have been developed by several organizations have been presented [6-9]. AASHTO 1993 and PCA 1984 methods are the first of these methods. Both methods have been used for long years by both designers and researchers.

Design methods are intensively based on experimental findings and mechanistic fundamentals. Mechanically it is important to know the maximum deflection in vertical direction and maximum stress happening in pavement under axle loads and thermal loads in concrete pavements [11,12]. This deflection and stress may be found by using the finite element method and also be calculated using the closed-form formulation. Westergaard equations which are formed of center, corner, and edge loadings according to critical loadings, have still survived until today and are used extensively $[1,2,3]$

As a result of edge loading while maximum stress takes place in the pavement, maximum deflection occurs when the load is near the corner. It is the key element for design to know the deflections and stresses under wheel loads. $[9,10,13]$

\section{Thickness Design in PCA 1984 Method}

The Portland Cement Association's (PCA) thickness-design method for concrete pavements was published in 1984. This method can be applied to jointed plain concrete pavement (JPCP), jointed reinforced concrete pavement (JRCP) and continuously reinforced concrete pavement (CRCP). The PCA 1984 method is a design methodology which has a mechanical and experimental infrastructure and is based on according to the maximum deflection which occur at vertical direction and the maximum stresses which the vehicles' load creates on the pavement. The maximum stresses and deflections which are obtained via mechanical methods are closely associated with the design tables and charts which are made by PCA. Fig 1 shows PCA design method's steps.

PCA 1984 method consists of erosion and fatigue analysis. For fatigue analysis, the ratio of maximum tensile stress of the pavement under repetitive traffic loads and the concrete's modulus of rupture are used. Cumulative damage concept (CDF) is used for the fatigue analysis and if CDF exceeds 1.00, it is assumed that the pavement thickness is not sufficient. [8,9]

In eq. (1) $D_{\mathrm{r}}$ is the cumulative damage ratio which will be caused throughout its lifespan 's design referring to all load groups, is the predicted number of repetitions for each load group and is the allowable number of repetitions for each load group.

$$
\mathrm{D}_{\mathrm{r}}=\sum \frac{\mathrm{n}_{\mathrm{i}}}{\mathrm{N}_{\mathrm{i}}}
$$

The Cumulative damage concept is used for both fatigue and erosion analysis. 
Fatigue analysis which is based on edge loading, is the most critical loading situation in terms of stress. The maximum stresses that occur for each axle group and the modulus of rupture of the concrete are compared and with the help of charts the allowable repetition numbers are specified. Fig 2 shows PCA fatigue analysis chart.

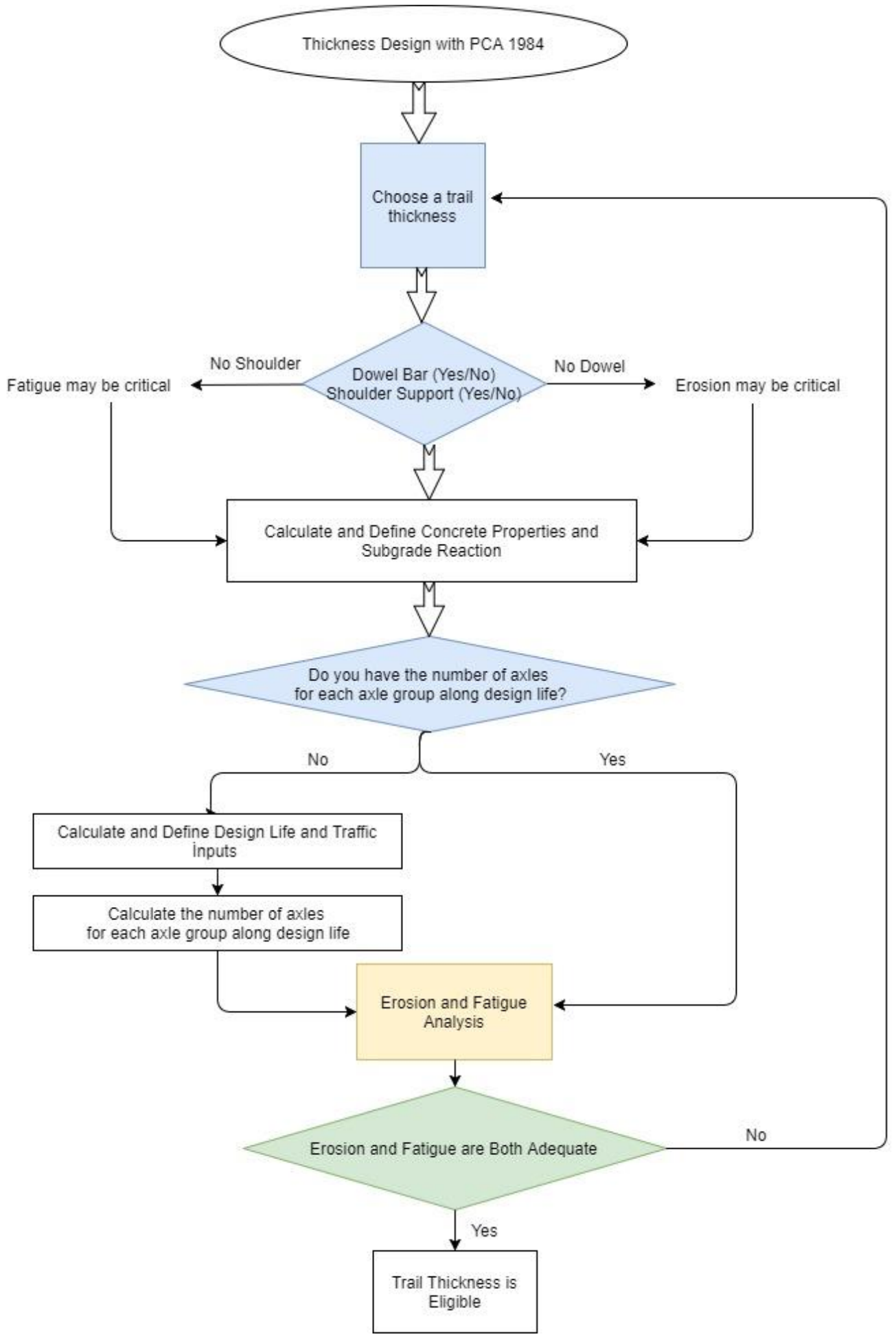

Fig. 1. PCA Flow Chart 


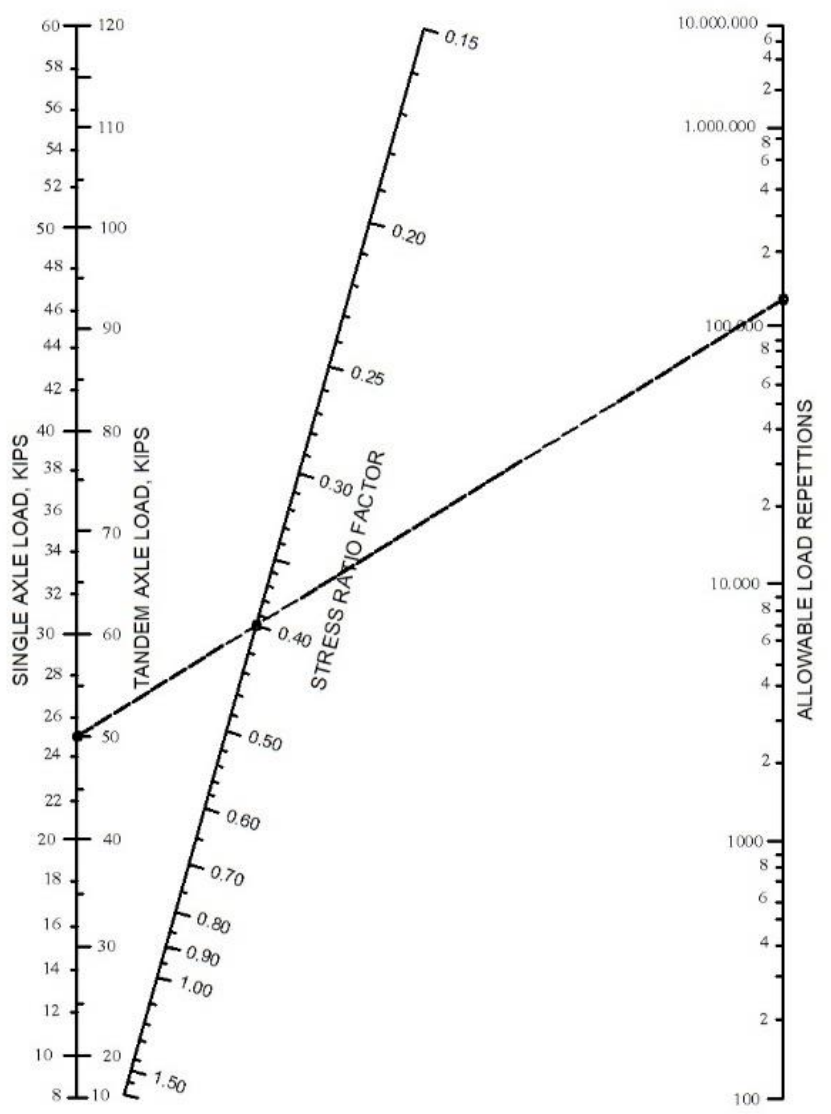

Fig. 2. PCA fatigue analysis chart (PCA, 1984)

The situation of corner loading is the most critical style of loading in terms of the deformation which occur in vertical direction. For this reason, deformation which occurs in the situation of corner loading, is used for erosion analysis. In the PCA method whether the dowel bars on the joints is important because it blocks the ground erosion and joint deterioration. Also in the tables presented in PCA 1984 have been prepared considering dowel bar and shoulder support.

Axle loads depending on fatigue, it's place and effect in erosion of every load group in the design of the PCA 1984 method should be found by looking at the charts one by one. In this situation, as a result of a single change in design, the analyses have to be repeated. And this causes a great waste of time for designers. Furthermore, the difficulty of using charts and how making a small mistake will have a massive effect on the design, makes it harder for designers.

The details of the PCA method haven't been specified clearly in literature. For this reason, designers have to use the tables and charts that the PCA 1984 design method presents. Lee and the others have analyzed the PCA method to eliminate this obligation in their study that they have carried out. As a result of this study, they have created several formula sets instead of tables and charts [5]. 


$$
\begin{aligned}
& \sigma_{\text {eq }}=\frac{6 * M_{e}}{h^{2}} * f_{1} * f_{2} * f_{3} * f_{4}
\end{aligned}
$$

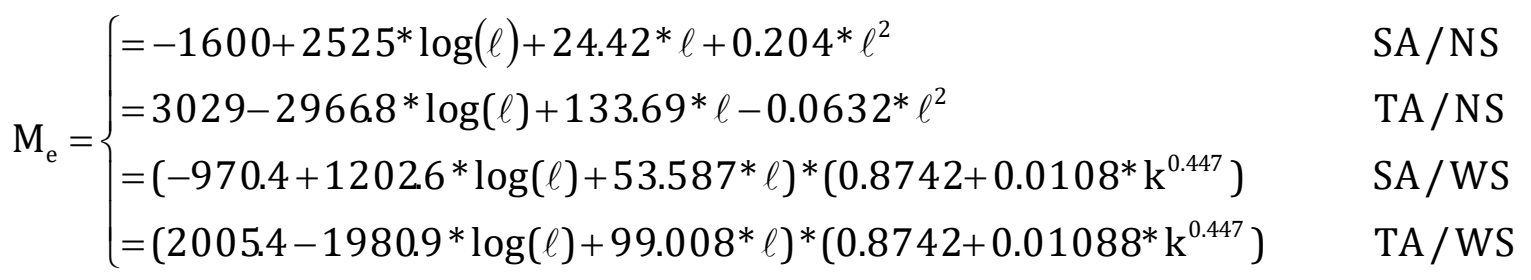

$$
\begin{aligned}
& \mathrm{f}_{1}= \begin{cases}(24 / \mathrm{SAL})^{0.06} *(\mathrm{SAL} / 18) & \mathrm{SA} \\
(48 / \mathrm{TAL})^{0.06} *(\mathrm{TAL} / 36) & \mathrm{TA}\end{cases} \\
& \mathrm{f}_{2}= \begin{cases}0.892+\mathrm{h} / 85.71-\mathrm{h}^{2} 3000 & \mathrm{NS} \\
1 & \text { WS }\end{cases} \\
& \mathrm{f}_{3}=0.894 \quad \text { for } \% 6 \text { truck at the slab edge }
\end{aligned}
$$

In Eq. (2) $\sigma_{\text {eq }}$ is the equivalent stress (psi), $h$ is the thickness of the pavement (in), $\ell$ is the relative stiffness of the subgrade system (in), $k$ is the modulus of subgrade reaction (pci) f1, f2, 33 and $f 4$ are the correction factors, SAL is single axle load, TAL is tandem axle load, WS means with shoulder, NS means no shoulder, TA and SA means tandem and single axle respectively.

$$
\begin{array}{cc}
\log \mathrm{N}_{\mathrm{f}}=11.737-12.077 *\left(\sigma_{\text {eq }} / \mathrm{S}_{\mathrm{C}}\right) & \sigma_{\text {eq }} / \mathrm{S}_{\mathrm{C}} \geq 0.55 \\
\mathrm{~N}_{\mathrm{f}}=\left(\frac{4.2577}{\sigma_{\text {eq }} / \mathrm{S}_{\mathrm{C}}-0.4325}\right)^{3.268} & 0.45<\sigma_{\text {eq }} / \mathrm{S}_{\mathrm{C}}<0.55 \\
\mathrm{~N}_{\mathrm{f}}=\text { Un limited } & \sigma_{\text {eq }} / \mathrm{S}_{\mathrm{C}} \leq 0.45
\end{array}
$$

In Eq. (3) $\mathrm{N}_{\mathrm{f}}$ is the allowable load repetitions $\mathrm{S}_{\mathrm{c}}$ is the concrete modulus of rapture.

\section{Thickness Design in AASHTO 1993}

In the instrument of the AASHTO 1993 method, the thickness of the slab and the reinforcement can be calculated for the concrete pavement. Either for its rigid superstructure design or its flexible superstructure design, AASHTO has constituted one of the most accepted design specifications by superstructure engineers and scientists. Because this constituted design is based on both experimental and mechanic foundations, this ensures it to get better results in design.

The AASHTO design method has published guides in the years 1972, 1986, 1993, 1998 and 2004. These guides were formed based on road tests and the data that was attained was stated with empirical formula. All these published guides, along with having the same concept with each other, each guide was developed with new additions. AASHTO 1993 method uses ESAL (Equivalent Single Axle Load) approach which is highly using approach by designers [14]. Figure 3 shows AASHTO design method's steps. 


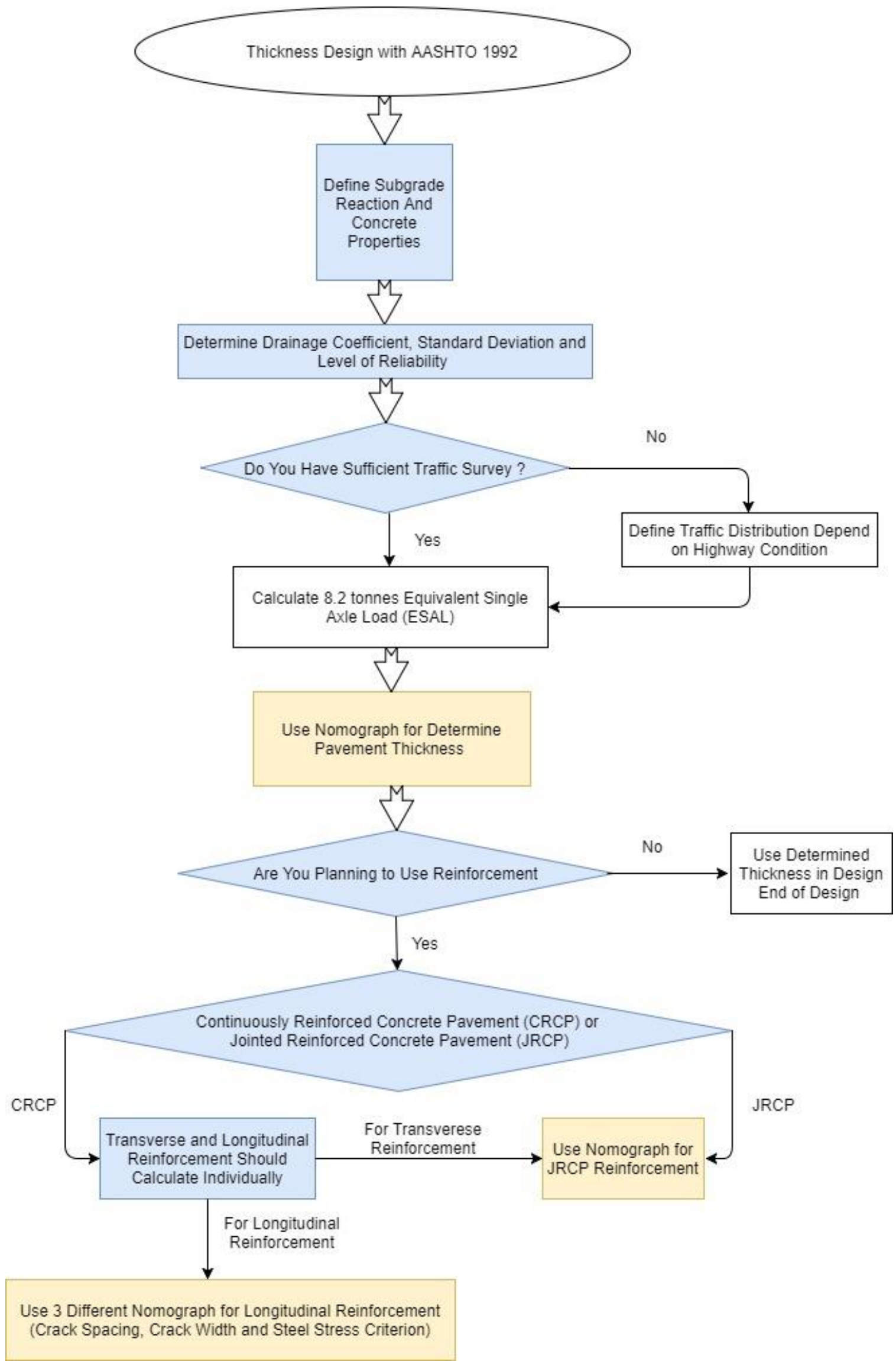

Fig. 3. AASHTO Flow Chart 
As in PCA 1984, in the AASHTO 1993 method a trail thickness is also not wanted. According to the equation prepared by AASHTO, the calculation of the thickness of the slab can be done by entering the required parameters.

In the equation of the calculation of thickness presented in the AASHTO 1993 method, the value of the thickness of the slab (D) both affects the other values and also is affected from them. To calculate the thickness of the slab by using this formula, can only be done by doing iteration. For this reason, the solution for this formula is quite difficult. Because of the difficulty of calculating the equation by hand, some charts have been developed for designers to make it easy for them.

According to AASHTO's 1993 design method, for the calculation of the thickness of the slab, as a result of experimental studies, the empirical formula on Eq 4 was obtained and doing the calculation of the thickness according to this formula was predicted.

In Eq (4) $S_{0}$ is the standard deviation, $Z_{R}$ is the reliability, $W_{18}$ the 18 kip equivalent single axle loads, $\mathrm{D}$ is the pavement thickness, $\mathrm{P}_{\mathrm{t}}$ is the terminal serviceability index, $\mathrm{C}_{\mathrm{d}}$ is the level of drainage, $\mathrm{k}$ is the effective module of subgrade reaction, $\mathrm{E}_{\mathrm{c}}$ is the modulus of elasticity of concrete, $\mathrm{J}$ is the load transfer coefficient, $\mathrm{S}_{\mathrm{c}}$ is the flexural strength of concrete $\triangle \mathrm{PSI}$ is the total change in serviceability index.

$$
\log _{10} W_{18}=S_{0} Z_{R}+7.35 \log _{10}(D+1)-0.06+\frac{\log _{10}\left[\frac{\Delta \text { PSI }}{4.5-1.5}\right]}{1+\frac{1.642 \times 10^{7}}{(D+1)^{8.46}}}+\ldots
$$

$$
\ldots+\left(4.22-0.32 \mathrm{P}_{\mathrm{t}}\right) \log \left[\frac{\mathrm{C}_{\mathrm{d}} \mathrm{S}_{\mathrm{c}}^{1}\left[\mathrm{D}^{0.75}-1.132\right]}{215.63 \mathrm{~J}\left[\mathrm{D}^{0.75}-\frac{18.42}{\left(\frac{\mathrm{E}_{\mathrm{c}}}{\mathrm{k}}\right)^{0.25}}\right]}\right]
$$

Critical stresses may occur between concrete pavements especially in joint areas during the passage of vehicles and due to environmental factors. Because of its concrete structure, it is more prone to cracks. These cracks increase with the passage of vehicles and environmental factors and reduces the lifespan of the road. Therefore, especially in joint areas, it has a great importance in terms of reinforcement crack inspection.

In the AASHTO 1993 design method, reinforcement designs were prepared separately for continuously reinforced concrete pavement and jointed reinforced concrete pavement. Once again based on experience, experimental studies and mechanic examinations, several formulas and chats were created to calculate the amount of reinforcement to be used in the design and the reinforcement measurements. 
The calculation of transverse reinforcement for continuously reinforced concrete pavements and the reinforcement calculations used for jointed reinforced concrete pavements are exactly the same. For the reinforcement calculation, the formula in Eq. 5 can be used.

$$
P_{S}=\frac{L F}{2 f_{s}} \times 100
$$

In $\mathrm{Eq}(5) \mathrm{L}$ is the length of pavement, $\mathrm{F}$ is the friction factor, fs is the steel working stress, Ps is the percent steel reinforcement for JRCP and transverse reinforcement in CRCP.

There are 3 different criteria in the longitudinal reinforcement calculation of CRCP. These criteria are the criterion of distance between cracks, the criterion of crack width and the criterion of allowable reinforcement stress. According to all three criteria, the required reinforcement ratio should be calculated and the highest donate ratio should be selected.

In Eq. (6), Eq. (7) and Eq. (8) $\bar{X}$ is the crack spacing, $f_{t}$ is the concrete tensile strength, $\alpha_{s}$ and $\alpha_{c}$ are steel and concrete thermal expansion coefficient respectively, $\phi$ is the bar diameter, $\sigma_{\mathrm{w}}$ is the tensile stress due to wheel load, $\mathrm{P}$ is the steel percentage, $\mathrm{Z}$ is the concrete shrinkage at 28 days.

$$
\bar{X}=\frac{1.32\left(1+\frac{f_{t}}{1000}\right)^{6.70} \times\left(1+\frac{\alpha_{s}}{2 \alpha_{c}}\right)^{1.15} x(1+\phi)^{2.19}}{\left(1+\frac{\sigma_{W}}{1000}\right)^{5.20} x(1+P)^{4.60} x(1+1000 Z)^{1.79}}
$$

In Eq (7) $\mathrm{CW}$ is the crack width.

$$
\mathrm{CW}=\frac{0.00932\left(1+\frac{\mathrm{f}_{\mathrm{t}}}{1000}\right)^{6.53} \mathrm{x}(1+\phi)^{2.20}}{\left(1+\frac{\sigma_{\mathrm{W}}}{1000}\right)^{4.91} \mathrm{x}(1+\mathrm{P})^{4.55}}
$$

In Eq. (8) $\sigma_{\mathrm{s}}$ is the steel stress. 


$$
\sigma_{S}=\frac{1.32\left(1+\frac{f_{t}}{1000}\right)^{6.70} \times\left(1+\frac{\alpha_{s}}{2 \alpha_{c}}\right)^{1.15} \times(1+\phi)^{2.19}}{\left(1+\frac{\sigma_{W}}{1000}\right)^{5.20} x(1+P)^{4.60} x(1+1000 Z)^{1.79}}
$$

\section{Maximum Principle Stress and Maximum Deflection with Westergaard}

In the studies that Westergaard (1926) has carried out, he developed formulas for the stress and deflections which will occur on the result of interior, edge and corner loading applied on the slab along with formulas that can also calculate deflections and stresses that will occur with the change of temperature. In the analysis of Westergaard, while the pressure between the slab and the ground is proportional with the deflection at that point, it is independent from the deflection at the other points. It is assumed that the ground and the slab are in full contact and the response of the ground to the slab is equal everywhere. This simplified acceptation is named liquid ground or the Winkler Foundation. [13]

For the analysis of the slabs, Westergaard equations, have been used to widely for a very long time to calculate the stresses which occur because of traffic loads and thermal loading. AASHTO and including PCA methods have also been used in many design methods.

Westergaard identified the corner, edge and interior loadings as critical loadings and tried to calculate the critical stresses which will occur on the slabs according to all three loading situations mathematically. Accordingly, considering all three loading situations he formulized the maximum stress and maximum deflections. Fig 4 shows critical load positions.

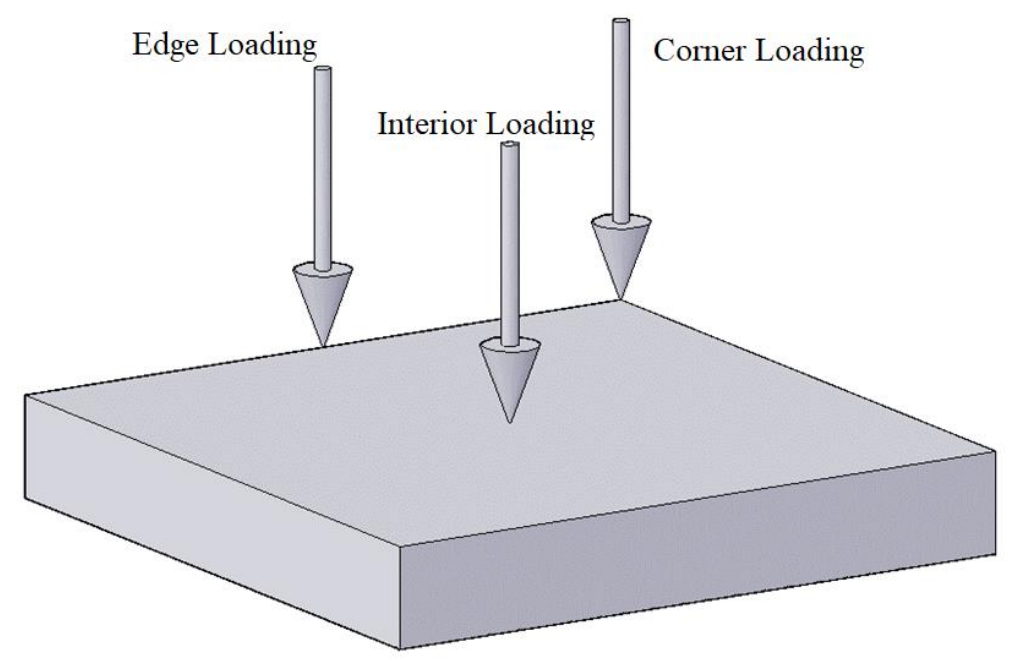

Fig. 4. Critical load positions 
For the corner loading situation, after Westergaard the maximum stresses and deflection equations which occur in the situation of corner loading were updated by Ioannides (1985).

In Eq. 9, Eq. 10, Eq. 11, Eq. 12, Eq. 13 and Eq. $14 \sigma_{c}$ and $\Delta_{c}$ are the maximum tensile stress and maximum deflection due to corner loading respectively, a is the radius of loading area, $\mathrm{D}$ is the pavement thickness, $\mathrm{P}$ is the wheel load, $\mathrm{l}$ is the radius of relative stiffness, $\mathrm{k}$ is the modulus of subgrade reaction.

$$
\begin{gathered}
\sigma_{\mathrm{C}}=\frac{3 \mathrm{P}}{\mathrm{D}^{2}}\left[1-\left(\frac{1.772 \mathrm{a}}{\mathrm{l}}\right)^{0.72}\right] \\
\Delta_{\mathrm{C}}=\frac{\mathrm{P}}{\mathrm{kl}^{2}}\left[1.205-0.69\left(\frac{1.772 \mathrm{a}}{\mathrm{l}}\right)\right]
\end{gathered}
$$

In Eq. 11 and $12 \sigma_{c}$ and $\Delta_{c}$ are the maximum tensile stress and maximum deflection due to edge loading respectively.

$$
\begin{gathered}
\sigma_{\mathrm{e}}=\frac{0.803 \mathrm{P}}{\mathrm{D}^{2}}\left[4 \log \left(\frac{\mathrm{l}}{\mathrm{a}}\right)+0.666\left(\frac{\mathrm{a}}{\mathrm{l}}\right)-0.034\right] \\
\Delta_{\mathrm{e}}=\frac{0.431 \mathrm{P}}{\mathrm{kl}^{2}}\left[1-0.82\left(\frac{\mathrm{a}}{\mathrm{l}}\right)\right]
\end{gathered}
$$

In Eq.13 and $14 \sigma_{c}$ and $\Delta_{c}$ are the maximum tensile stress and maximum deflection due to interior loading respectively.

$$
\begin{gathered}
\sigma_{\mathrm{i}}=\frac{0.316 \mathrm{P}}{\mathrm{D}^{2}}\left[4 \log \left(\frac{\mathrm{l}}{\mathrm{b}}\right)+1.069\right] \\
\Delta_{\mathrm{i}}=\frac{\mathrm{P}}{8 \mathrm{kl}^{2}}\left[1+\frac{1}{2 \pi}\left[\ln \left(\frac{\mathrm{a}}{2 \mathrm{l}}\right)-0.673\right]\left(\frac{\mathrm{a}}{\mathrm{l}}\right)^{2}\right]
\end{gathered}
$$

b may be written as,

$$
\begin{array}{ll}
b=a & \text { when } a \geq 1.724 D \\
b=\sqrt{1.6 a^{2}+D^{2}}-0.75 h & \text { when } a<1.724 D
\end{array}
$$


When looked at all three loading situations in terms of deflection, the most critical loading situation occurs as a result of corner loading. For this reason, deflections which are attained by corner loading are used in erosion analysis in the PCA method. Because of edge loading, maximum principle stresses occur. Because stresses that occur by edge loading brings forth maximum stresses, the corner loading situation is considered in fatigue analyses.

\section{SDU.Pave.R Software}

The slab thickness design for concrete roads are affected from many properties such as the properties of the concrete, traffic loads and expectations from the design. For this reason, different scenarios being established and analyses being done for different circumstances are important in terms of finding the right thickness of the slab. While slabs which are thicker than they should be increase the cost, concrete slabs which are designed thinner than they should be deteriorate earlier, nevertheless causing economic loss. For this reason, it is quite important to determine the right thickness of the slab.

Although design programs which are presented for concrete roads guide the designer with the instructions they give, identifying different scenarios to determine the right thickness of the slab and making a design of the thickness of the slab according to these scenarios are not always possible. Because there are too many detailed calculations in the formulas of the presented design methods. Furthermore, charts which are used to determine the thickness and reinforcement, are often misread. Designers who do these calculations by hand either have difficulty or make mistakes in determining the thickness of the slab.

In this study, a user-friendly software was developed for overcoming the difficulties of the calculations of reinforcements and the thickness of the concrete roads. With the help of this user-friendly software, the solutions of the Westergaard equation can be easily done with PCA 1984 and AASHTO 1993. The home page of SDU.Pave.R have been shown in Fig 5.

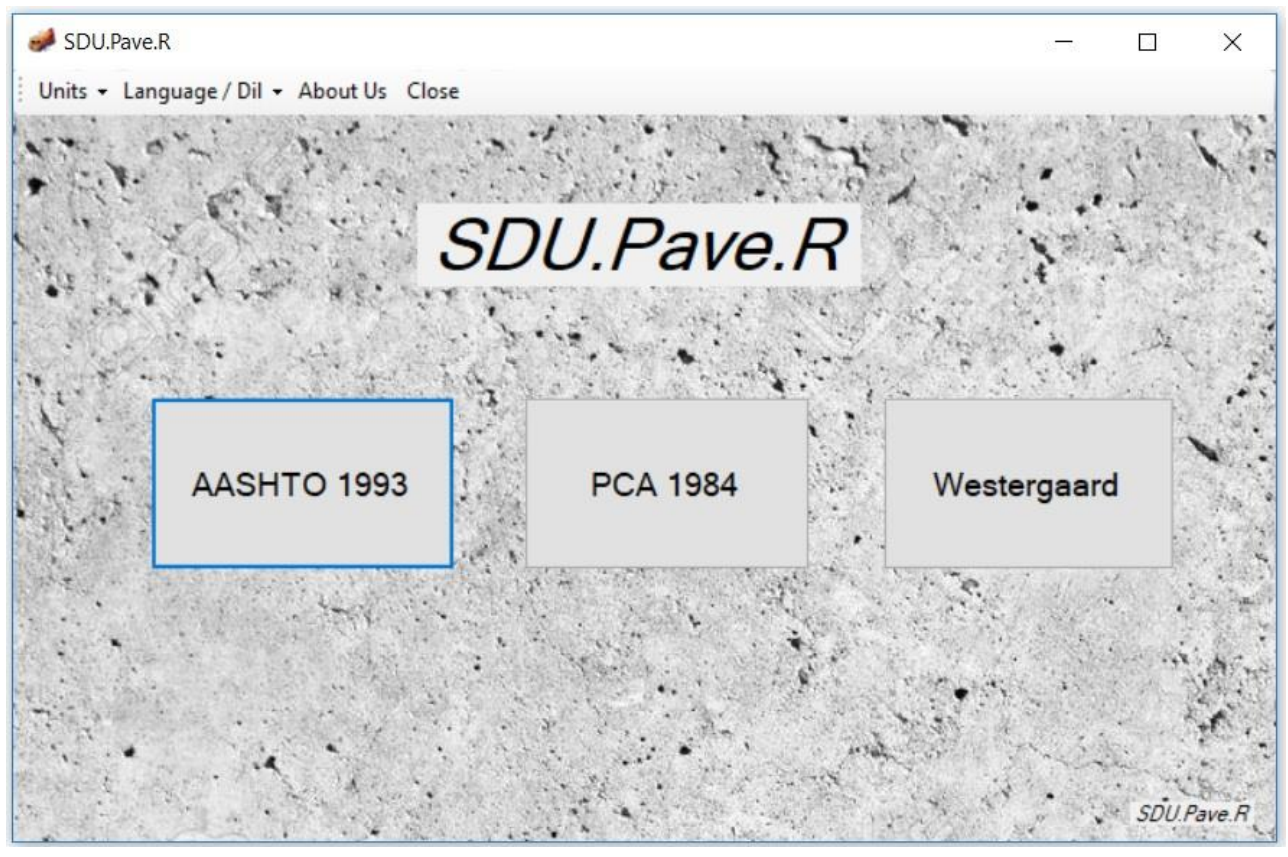

Fig. 5 Home page of SDU.Pave.R 
Through this software both the thickness analysis and donate calculations can be done using AASHTO 1993. The donate calculation is done separately for continuously reinforced concrete pavements and separately for jointed reinforced concrete pavements. Moreover, you can see the recommended values for the selected input when you click on the question marks buttons in the software. In this way, the user can make a more accurate design by getting information about inputs he doesn't know of.

For calculate slab thickness and steel percentage according to AASHTO design method with SDU.Pave.R software, we used example parameters given in Table 1. Steel percentage calculated for JRCP (Jointed Reinforced Concrete Pavement). The results of analyzes which made with SDU.Pave.R also given in Table 1 as output. When the results compare with the results obtained from the charts given in AASHTO Design Guide, we may see the results are totally overlapping. Instead of using AASHTO charts, thickness and steel percentage can easily calculate with SDU.Pave.R.

\begin{tabular}{lr}
$\begin{array}{l}\text { Table 1. AASHTO Design Example Inputs and Outputs } \\
\text { Input }\end{array}$ & $\begin{array}{r}\text { Value } \\
\text { Modulus of Sub. Reaction }\left(\mathrm{MN} / \mathrm{m}^{3}\right)\end{array}$ \\
Standard Deviation & 0.3 \\
Drainage Coefficient & 1 \\
Elastic Modulus of Concrete (MPa) & 35000 \\
Number of Axle Load (million) & 6 \\
Initial Serviceability Index & 4.20 \\
Terminal Serviceability Index & 2.6 \\
Concrete Modulus of Rupture (MPa) & 4.5 \\
Load Transfer Coefficient & 3.2 \\
Slab Length (m) & 12 \\
Friction Factor & 1.5 \\
Steel Working Stress (MPa) & 2000 \\
\hline Output & 25.7 \\
Slab Thickness (cm) & 0.1 \\
Steel Percentage $(\%)$ &
\end{tabular}

In the PCA 1984 method, fatigue and erosion analyses should be done for each axle type and axle weight separately. In these analyses, the analyses should be repeated one by one for each load by looking at the table and charts. This process is a long and troublesome process. The SDU.Pave.R software allows these analyses to be done quite easily and without errors. Furthermore, future traffic and truck quantities can be calculated with the help of the traffic option in the PCA 1984 module. The AASHTO thickness and reinforcement design page of SDU.Pave.R has been shown in Fig 6. 


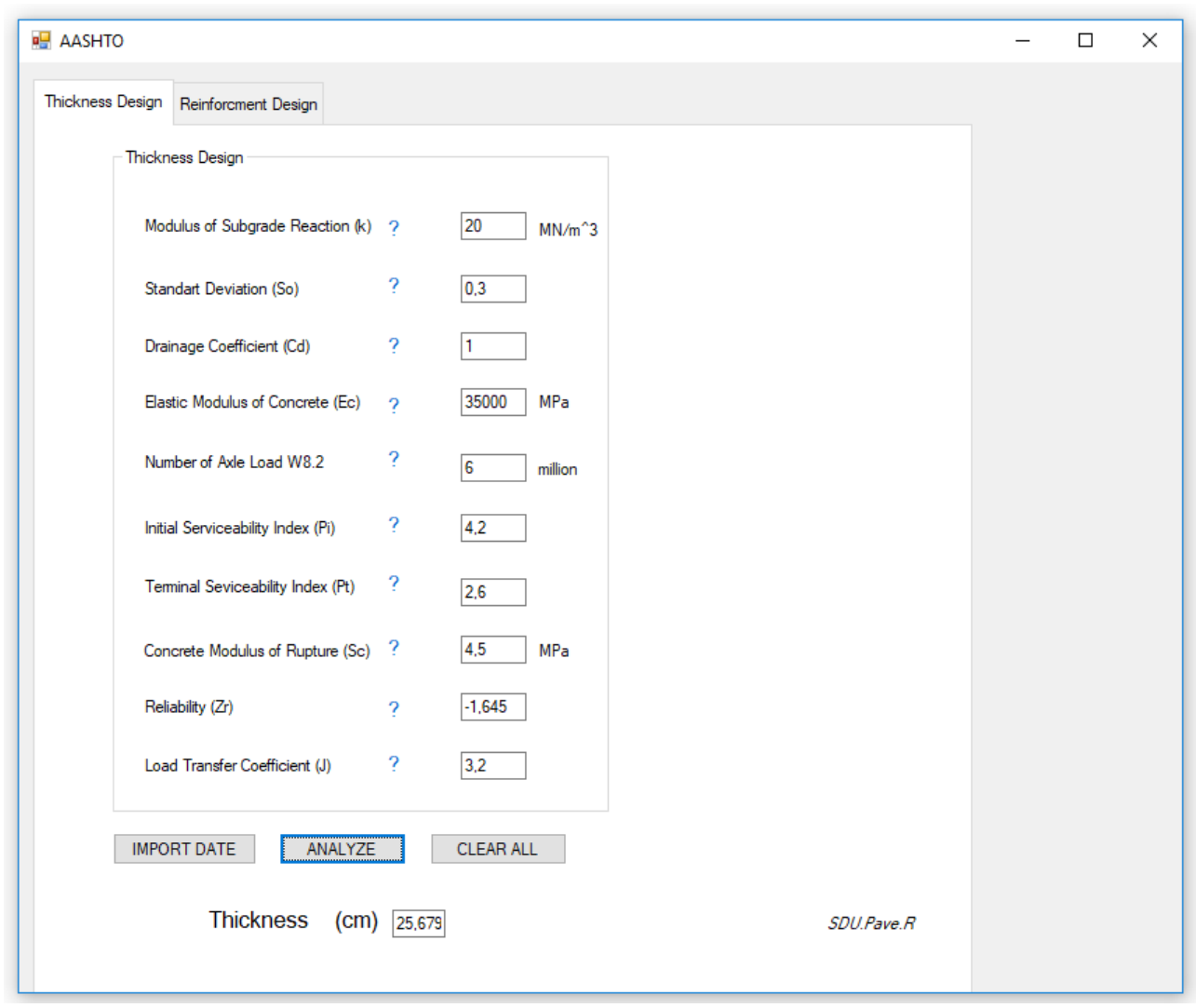

Fig. 6. AASHTO Thickness and Reinforcement Design with SDU.Pave.R

SDU.Pave.R PCA module also can help designers and researchers. Instead of using PCA method's tables and charts, fatigue and erosion analyzes may run easily with SDU.Pave.R software. For an example we chose trail pavement thickness as $25.5 \mathrm{~cm}$. We considered doweled joint and no shoulder situation. The parameters using for this example presented Table 2. Fatigue analyze result with SDU.Pave.R software has been shown in Fig 7. End of the analyzes made with SDU.Pave.R fatigue and erosion were calculated as \%84.92 and \%18.71 respectively.

Table 2. PCA Design Example Inputs and Outputs

\begin{tabular}{lr} 
Input & Value \\
\hline Trail Pavement Thickness $(\mathrm{cm})$ & 25.5 \\
Modulus of Sub. Reaction $\left(\mathrm{MN} / \mathrm{m}^{3}\right)$ & 20 \\
Concrete Modulus of Rupture $(\mathrm{MPa})$ & 4.5 \\
Elastic Modulus of Concrete $(\mathrm{MPa})$ & 35000 \\
Poisson Ratio of Concrete & 0.13 \\
\hline Load Safety Factor & 1.1 \\
Average Daily Traffic (Both Direction) & 3500 \\
Proportion of Trucks in Right Line & 0.75 \\
Design Period (Years) & 30 \\
\hline
\end{tabular}




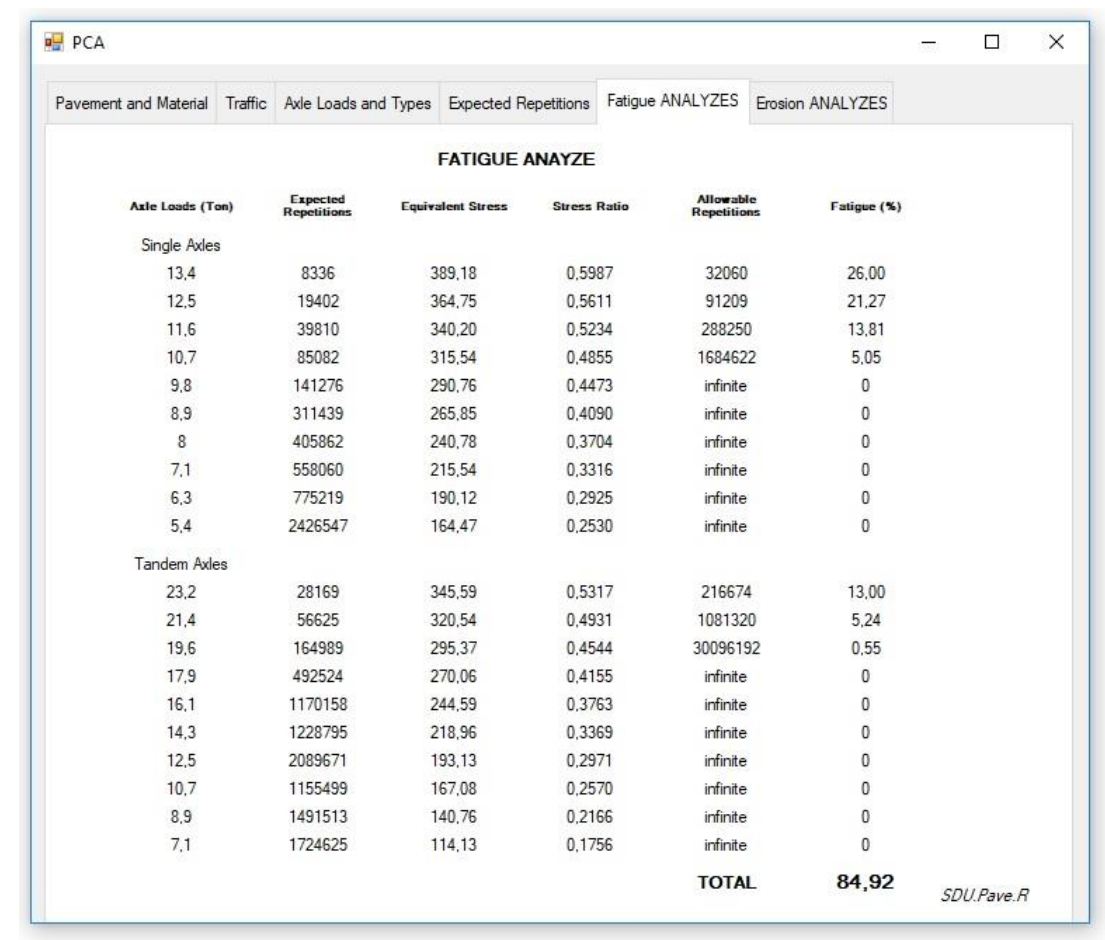

Fig. 7. PCA Fatigue Analyses with SDU.Pave.R

The formulas used in Westergaard analyses are quite complex. Therefore, it takes a long time to repeat the analysis according to different loading scenarios. With the SDU.Pave.R software, analyses can be performed according to the three critical loading situations (interior, edge, corner). Furthermore, the loading format is visualized according to the selected situation, making it easier for users (Fig 8).

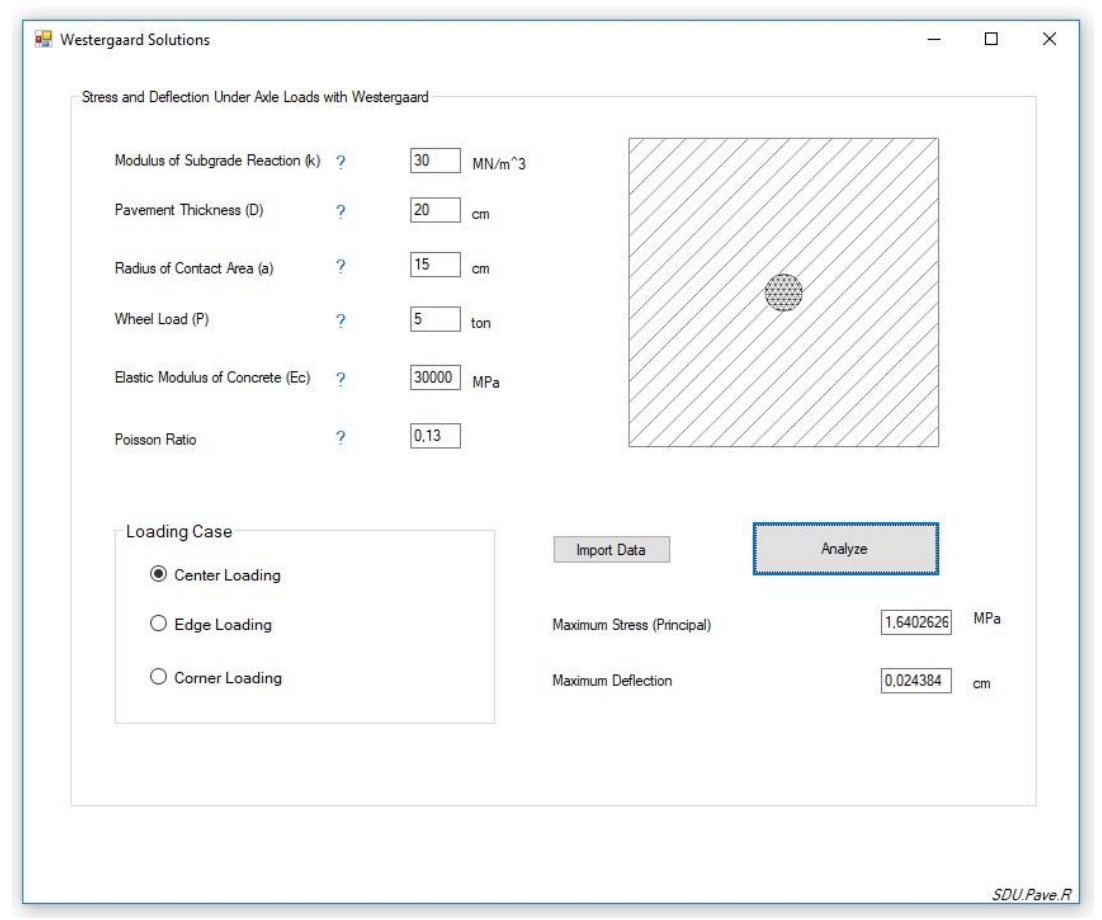

Fig. 8. Westergaard Solution with SDU.Pave.R 


\section{Concluding Remarks}

In this study, a user-friendly software including the AASHTO 1993 and PCA 1984 methods which are the most used methods for concrete slab design and the Westergaard equations has been developed. Thanks to this software named SDU.Pave.R, it has been ensured that the design of the concrete slab thickness and reinforcement can be done quickly and easily without depending on charts and equations. There is no other software offering design methods under the same software. The SDU.Pave.R has bridged the gap and has allowed users who want to calculate the concrete slab thickness with different design methods. Furthermore, the fact that the software offers both Turkish and English language support makes the program easier to use from different countries. In addition, with the choice of the American and SI unit system in the software, it allows extensive usage for users in countries using a different unit system.

\section{Acknowledgements}

The financial support of the ÖYP Unit of Süleyman Demirel University is gratefully acknowledged.

\section{References}

[1] Fitch, M. Bellefontaine, Ohio: Home of America's Oldest Concrete Pavement. 1996

[2] Delatte, N. J., Concrete Pavement Design, Construction, and Performance. Crc Press, 2014.

[3] Huang, Y. H., Pavement Analysis and Design. Pearson Education Inc. 2004.

[4] Yoder, E. J., Witczak, M. W., Principles of Pavement Design. John Wiley and Sons. 1975.

[5] Lee, Ying-Haur, et al. Modified Portland cement association stress analysis and thickness design procedures. Transportation Research Record Journal of the Transportation Research Board, 1568: 77-88. 1997.

[6] AASHTO, Guide for Design of Pavement Structures. Washington DC, American Association of State Highway and Transportation Official, 1986.

[7] AASHTO, Guide for Design of Pavement Structures. Washington DC, American Association of State Highway and Transportation Official, 1993.

[8] Portland Cement Association, Thickness Design for Concrete Pavements. Skokie, IL: Portland Cement Association, 1966.

[9] Portland Cement Association, Thickness Design for Concrete Highway and Street Pavements, Engineering Bulletin EB109P. Skokie, IL: Portland Cement Association, 1984.

[10] Maitra, S. R., Reddy, K. S., Ramachandra, L. S., Estimation of Critical Stress in Jointed Concrete Pavement. Procedia-Social and Behavioral Sciences, 104, 208-217, 2013.

[11] Choi, S., Na, B. U., Won, M. C., Mesoscale Analysis of Continuously Reinforced Concrete Pavement Behavior Subjected to Environmental Loading. Construction and Building Materials, 112, 447-456, 2016. 
[12] Sabih, G., Tarefder, R. A., Impact of Variability of Mechanical and Thermal Properties of Concrete on Predicted Performance of Jointed Plain Concrete Pavements. International Journal of Pavement Research and Technology, 9(6), 436-444, 2016.

[13] Westergaard, H. M ., Analysis of Stresses in Concrete Pavement Due to Variations of Temperature. Proceedings, Highway Research Board, Vol. 6, pp. 201-215, 1926.

[14] Bordelon, A. C., Hiller, J. E., Roesler, J. R., Cervantes, V. G., Investigation of ESALs versus Load Spectra for Rigid Pavement Design. Airfield and Highway Pavements 488-499, 2015. 